\title{
Geometric Stiffness Effects on Data Recovery of an Idealized Mast/Blanket Model
}

\author{
Paul A. Bosela \\ Cleveland State University, p.bosela@csuohio.edu \\ D. R. Ludwiczak \\ NASA Lewis Research Center
}

Follow this and additional works at: https://engagedscholarship.csuohio.edu/encee_facpub

Part of the Structures and Materials Commons

How does access to this work benefit you? Let us know!

\section{Publisher's Statement}

NOTICE: this is the author's version of a work that was accepted for publication in Computers \& Structures. Changes resulting from the publishing process, such as peer review, editing, corrections, structural formatting, and other quality control mechanisms may not be reflected in this document. Changes may have been made to this work since it was submitted for publication. A definitive version was subsequently published in Computers \& Structures, 59, 1 , (04-03-1996); 10.1016/0045-7949(96)00236-2

\section{Original Citation}

Bosela P. A., Ludwiczak D. R. (1996). Geometric Stiffness Effects on Data Recovery of an Idealized Mast/ Blanket Model. Computers \& Structures, 59, 1, 67-79 DOI: 10.1016/0045-7949(96)00236-2

This Article is brought to you for free and open access by the Civil and Environmental Engineering at EngagedScholarship@CSU. It has been accepted for inclusion in Civil and Environmental Engineering Faculty Publications by an authorized administrator of EngagedScholarship@CSU. For more information, please contact library.es@csuohio.edu. 


\title{
GEOMETRIC STIFFNESS EFFECTS ON DATA RECOVERY OF AN IDEALIZED MAST/BLANKET MODEL
}

\author{
P. A. Bosela† and D. R. Ludwiczak $\ddagger$ \\ $\dagger$ Department of Engineering Technology, Cleveland State University, Cleveland, OH 44I15, U.S.A. \\ ¥Engineering Directorate, Structural Systems Division, Dynamics Branch, \\ NASA Lewis Research Center, Cleveland, OH 44135, U.S.A.
}

\section{NOTATION}

E Young's modulus (psi)

$F(t)$ forcing function (lb)

$I_{x} \quad$ moment of inertia about $X$-axis $\left(\right.$ in $\left.^{4}\right)$

$I_{y}$ moment of inertia about $Y$-axis $\left(\mathrm{in}^{4}\right)$

$K_{\text {ca }}$ partition of stiffness matrix correspondng to active degrees of freedom

$[K]$ stiffness matrix

$\left[K_{e}\right]$ elastic stiffness matrix

$\left[K_{\mathrm{g}}\right]$ geometric (initial stress) stiffness matrix

$\left[K_{t}\right]$ tangential stiffness matrix $\left(\left[K_{\epsilon}\right]+\left[K_{g}\right]\right)$

$L \quad$ length of beam (in)

$M_{\text {ca }}$ partition of mass matrix corresponding to active degrees of freedom

$n \quad$ designation of the number of possible buckling loads

$P_{\text {cr }} \quad$ critical buckling load (lb)

$R_{\mathrm{c}} \quad$ column matrix of constraint reactions

$r \quad$ result of equation (4)

$\{R\}$ column matrix of forces

$T$ time (s)

$U_{5}$ displacement of degree of freedom 5 (free end of beam) (in)

$U_{\mathrm{a}} \quad$ column matrix of unconstrained (active) degrees of freedom

$U_{\mathrm{a}}$ column matrix of accelerations of unconstrained (active) degrees of freedom

$\{U\}$ column matrix of displacements

$W$ distributed load $\left(\mathrm{lb}^{\mathrm{b}} \mathrm{in}^{-1}\right)$

$y_{\max }$ maximum deflection (in) $\begin{array}{ll}\rho & \text { linear weight of string }\left(\mathrm{lb} \mathrm{in}^{-1}\right) \\ v & \text { Poisson's ratio }\end{array}$

\section{INTRODUCTION}

The photovoltaic arrays for the international space station consist of a pre-tensioned blanket of solar collectors, and a deployable mast. NASA uses MSC/NASTRAN finite element program for modeling the dynamic response of the structure due to various loading conditions, such as plume impingement during shuttle docking. This finite element program uses the updated stiffness matrix (elastic plus geometric, or initial stress stiffness matrix) in determining the natural frequencies and mode shapes, as well as the dynamic response, of a preloaded structure. However, during the data recovery phase, during which the moment and shear at the supports, and internal stresses are determined, only the elastic stiffness is used. Previous works [1-5] have considered the effect of pre-load on natural frequencies and mode shapes. The purpose of this study is to determine whether the absence of the geometric stiffness terms during data recovery significantly affects the moment and shear calculations at the nodes. 

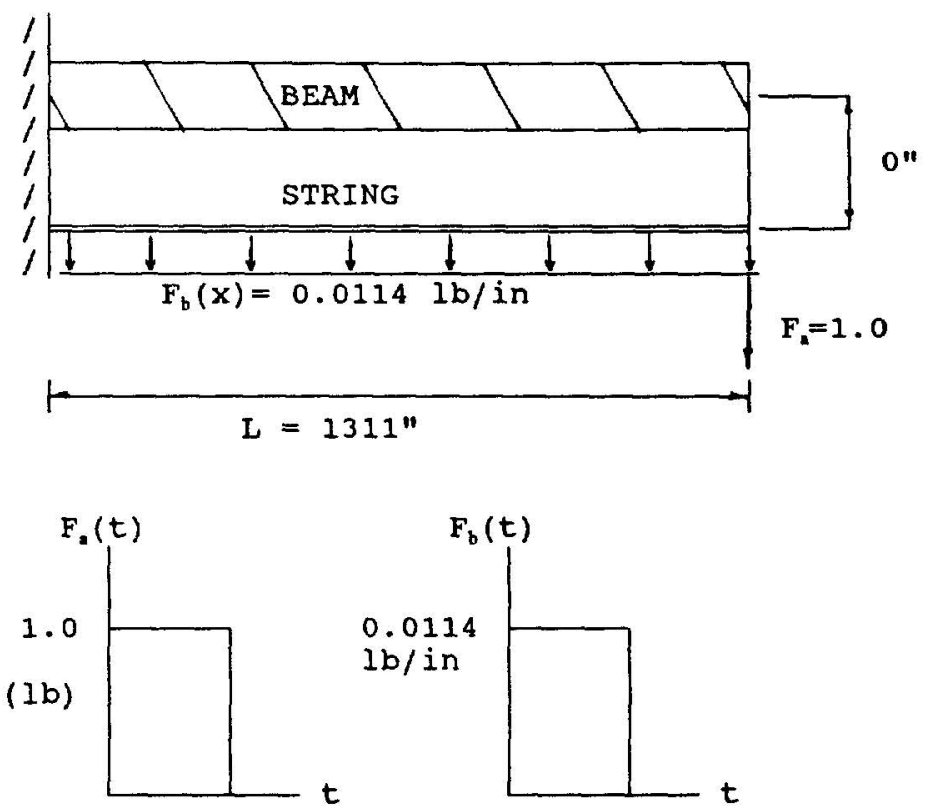

\section{Element Data}

Mast

$\mathrm{A}=9.29 \mathrm{in}^{2}$

$I x=I Y=2558.3 i n^{4}$

$\mathrm{E}=10.1 \times 10^{8} \mathrm{psi}$

$v=0.33$

$\rho=2.133 \mathrm{lb} / \mathrm{in}$

\section{Blanket}

$A=9.29 \mathrm{in}^{2}$

$I x=I y=2558.3 i n^{4}$

$\mathbf{E}=10.1 \times 10^{8} \mathrm{psi}$

$v=0.33$

$\rho=2.133 \mathrm{Ib} / \mathrm{in}$

Fig. 1. Idealized PV array (mast/blanket model).

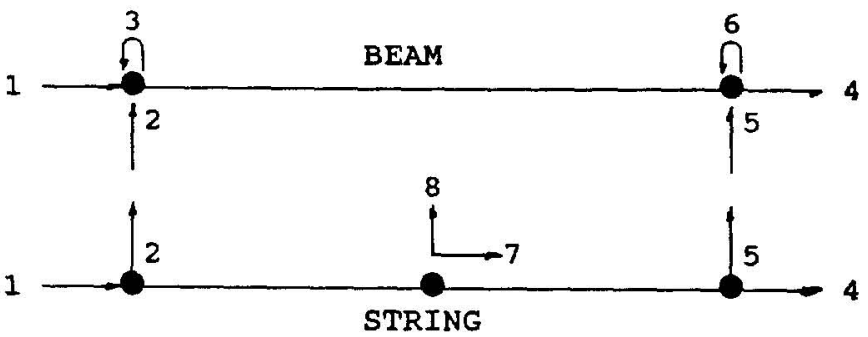

Fig. 2. Bellini's three-element model.

In this study, the PV array has been idealized into a cantilever beam with an attached pretensioned cable (Fig. 1). Various mesh refinements were used to check the fidelity of the model.

$\dagger$ Dr Paul X. Bellini, Professor of Civil Engineering, Cleveland State University, Cleveland, $\mathrm{OH} 44114$, U.S.A.

\section{THREE-ELEMENT MODEL.}

Two different impulse loads were examined. For case (a), a load of $F(t)=1.0$, for $0<t<1.36$ was applied at the end node of the cantilever beam. For case (b), a distributed load of $F(t)=0.0114 \mathrm{lb}^{-1}$ over the same time increment was applied to the string.

Bellinit prepared a primitive model of the system ( 1 beam element and 2 string elements) and developed 
the corresponding stiffness and mass matrices of the model shown in Fig. 2.

Boslea's program BMTRUSS.FOR was also used to assemble the stiffness and mass matrices and verified Bellini's manual calculations. This program uses Bernoulli beam elements and the consistent geometric stiffness matrix and the consistent mass matrix to model the beam, and uniaxial truss elements to model the string. Gloal stiffness and mass matrices are assembled, a Cholesky decomposition is used to convert the generalized eigenvalue problem to the standard form, and subsequently the Jacobi method is applied to determine the natural frequencies and mode shapes.

\section{STATIC DEFLECTION}

Before proceeding with the dynamic analysis, one can help ascertain the "reasonableness" of the solution by first considering a static analysis. If one considers a cantilever beam with no pre-load, and applies a concentrated load of one pound at the free end, the following is obtained:

$$
\begin{aligned}
Y_{\max } & =F L^{3} /(3 E I) \\
& =\frac{(1) \mathrm{lb}(1311)^{3} \mathrm{in}^{3} \mathrm{in}^{2}}{3\left(10.1 \times 10^{6}\right) \mathrm{lb}(108.9) \mathrm{in}^{4}} \\
& =0.6829 \mathrm{in} .
\end{aligned}
$$

By letting $n=1$, the first buckling load is determined to be $1576 \mathrm{lb}$, which is much less that the stipulated pre-load of $150 \mathrm{lb}$ in this problem. Thus, displacements of the case where $P=150 \mathrm{lb}$ should be well within the elastic range and material nonlinearity will not be a factor.

When one considers the preload, Bellini's methodology yields

$$
u_{5}=\frac{r(20)(1-p)}{3\left(20-60 p+25 p^{2}\right)},
$$

where

$$
r=\frac{R L^{3}}{E I} \quad \text { and } \quad p=\frac{P L^{2}}{30 E I}
$$

Substitution yields

$$
u_{5}=0.6724 \mathrm{in}
$$

Similarly, using $[K]$ generated by BMTRUSS.FOR yields

$$
\begin{gathered}
{[K]\{U\}=\{R\}} \\
\{U\}=[K]^{-1}\{R\}
\end{gathered}
$$

$$
\begin{aligned}
{\left[\begin{array}{c}
U 7 \\
U 8 \\
U 4 \\
U 5 \\
U 6
\end{array}\right]=\left[\begin{array}{ccccc}
1066 & 0 & -533.1 & 0 & 0 \\
0 & 0.4577 & 0 & -0.2288 & 0 \\
-533.1 & 0 & 8,237 & 0 & 0 \\
0 & -0.2288 & 0 & 5.949 & -3825 \\
0 & 0 & 0 & -3825 & 3,330,000
\end{array}\right]\left[\begin{array}{l}
0 \\
0 \\
0 \\
1 \\
0
\end{array}\right] } \\
=\left[\begin{array}{c}
0 \\
0.34689 \\
0 \\
0.69394 \\
0.00079709
\end{array}\right] .
\end{aligned}
$$

Note that the effect of the string has been neglected.

The critical buckling loads are

$$
\begin{aligned}
P_{\mathrm{cr}} & =\frac{n^{2} E I}{4 L^{2}} \\
& =\frac{n^{2}\left(10.1 \times 10^{6}\right) \mathrm{lb}(108.9) \mathrm{in}^{4}}{(4) \mathrm{in}^{2}(1311) 2 \mathrm{in}^{2}} .
\end{aligned}
$$

$\dagger$ Jim Chien, Dynamic Analyst, Analex Corporation, Cleveland, $\mathrm{OH} 44135$, U.S.A.
Thus, $y_{\max }=U_{5}=0.6939 \mathrm{in}$, which represents the pre-loaded beam free end static displacement, which is very close $(1.5 \%)$ to the solution of a simple cantilever beam, as would be expected since the pre-load was very small (10\% of the critical buckling load).

\section{TWENTY-ELEMENT MODEL}

Chien $\dagger$ investigated the same problem using 10 beam elements and 10 string elements (Fig. 3), 


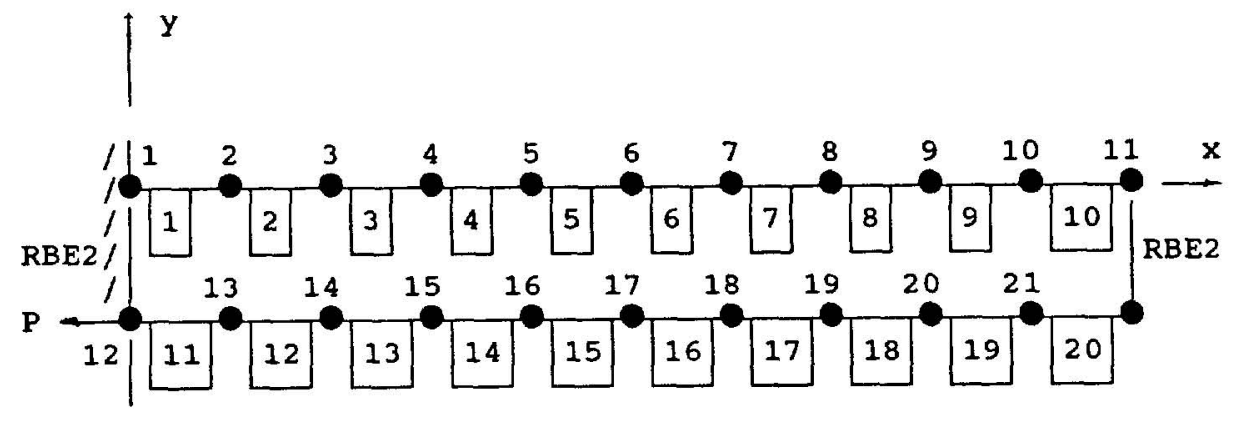

$$
\begin{array}{ll}
\text { Elements } 10 \text { to } 10 \text { are CBEAM } & \begin{array}{l}
A=1.0 \mathrm{in}^{2} \\
I x=I y=108.9 \mathrm{in}^{4}
\end{array} \\
& p=0.22961 \mathrm{~b} / \mathrm{in} \\
\text { Elements } 11 \text { to } 20 \text { are CBEAM } & \\
& \begin{array}{l}
\mathrm{A}=0.0346 \mathrm{in}^{2} \\
\end{array} \\
& p=0.2685 \mathrm{ib} / \mathrm{in}
\end{array}
$$

Coupmass option card used.

Material properties

$$
\begin{aligned}
& E=10.1 \times 10^{6} \\
& v=0.33
\end{aligned}
$$

Fig. 3. Chen's NASTRAN model.

utilizing MSC/NASTRAN. However, the string elements had to be modeled using beam elements with very small moments of inertia $\left(I_{x}=I_{y}=1.0 \times 10^{-4} \mathrm{in}\right)$, rather than with truss elements. A similar model was used by the author in his computer program BMSTRNG.FOR, which was a modification of BMTRUSS.FOR, with beam elements with very small moment of inertia utilized instead of truss elements to model the string.

Table 1 compares the first 12 frequencies of vibration obtained by MSC/NASTRAN and BM-
STRNG.FOR with 10 beam and 10 string elements (BS10\&10). As can be seen from this table, the results are essentially identical. The other runs listed in the table were done to show monotonic convergence of the lower frequencies. BT 1\&2 was for a mesh with the beam modeled with one beam element, and the string

\begin{tabular}{|c|c|c|c|c|c|c|c|}
\hline \multirow{2}{*}{$\begin{array}{c}\text { Frequency } \\
\text { rank }\end{array}$} & \multicolumn{6}{|c|}{$\begin{array}{l}\text { Frequency } \\
\left(\mathrm{rad} \mathrm{s}^{-1}\right)\end{array}$} & \multirow[b]{2}{*}{$\%$ diff } \\
\hline & BT $1 \& 2$ & BS1\&2 & BS2\&2 & BS4\&4 & BS10\&10 & NASTRAN & \\
\hline 1 & 1.1616 & 1.1598 & 1.1598 & 1.0766 & 1.0381 & 1.0378 & 0.03 \\
\hline 2 & 2.1828 & 2.1467 & 2.1454 & 2.0297 & 1.9785 & 1.9779 & 0.03 \\
\hline 3 & 20.141 & 2.9785 & 2.9752 & 2.8065 & 2.7685 & 2.7677 & 0.03 \\
\hline 4 & 66.977 & 23.712 & 15.683 & 3.7649 & 3.6659 & 3.6649 & 0.03 \\
\hline 5 & 146.90 & 56.742 & 54.995 & 4.9486 & 4.7087 & 4.7075 & 0.03 \\
\hline 6 & & 148.66 & 56.738 & 6.2931 & 5.8052 & 5.8037 & 0.03 \\
\hline 7 & & & 121.08 & 7.9674 & 6.9239 & 6.9223 & 0.02 \\
\hline 8 & & & 143.27 & 15.916 & 8.0562 & 8.0545 & 0.02 \\
\hline 9 & & & 450.91 & 46.008 & 9.1998 & 9.1981 & 0.02 \\
\hline 0 & & & & 52.984 & 10.3520 & 10.3498 & 0.02 \\
\hline 1 & & & & 92.700 & 11.5731 & 11.5741 & 0.01 \\
\hline 2 & & & & 110.85 & 12.7512 & 12.7508 & 0.00 \\
\hline
\end{tabular}
modeled with one truss element, comparable to Bellini's model. BS1\&2 was a similar model, except that the string was modeled using two beam elements with a very small moment of inertia $\left(1 \times 10^{-4} \mathrm{in}^{4}\right)$, similar to the string elements in the NASTRAN

Table 1. Comparison of frequencies 
Table 2. Comparison of maximum displacements for various meshes and loading conditions

\begin{tabular}{lcc}
\hline & Time $\left(\mathrm{s}^{-1}\right)$ & Max displacement (in) \\
\hline & Case $(a) \mathrm{F}(\mathrm{b})=1.016$ \\
BS1\&2 & 1.32 & 1.14943 \\
BS2\&2 & 1.3736 & 1.15367 \\
BS4\&4 & 1.3464 & 1.07224 \\
BS10\&10 & 1.2988 & 1.04029 \\
& Case $(b) \mathrm{F}(\mathrm{b})=0.0114 \mathrm{lb} \mathrm{in}^{-1}$ \\
BS1\&2 & 1.92 & 6.59467 \\
BS2\&2 & 1.836 & 6.50856 \\
BS4\&4 & 2.0808 & 6.45206 \\
BS10\&10 & 2.0740 & 6.50548 \\
\hline
\end{tabular}

model. Similarly, BS2\&2 and BS4\&4 included two beam, two string, and four beam, four string elements, respectively.

Table 2 compares the maximum displacements for BMTRUSS.FOR, with beam elements with very small moment of inertia utilized instead of truss elements to model the string.

Table 1 compares the first 12 frequencies of vibration obtained by MSC/NASTRAN and BMSTRNG.FOR with 10 beam and 10 string elements (BS10\& 10). As can be seen from this table, the results are essentially identical. The other runs listed in the table were done to show monotonic convergence of the lower frequencies. BT $1 \& 2$ was for a mesh with the beam modeled with one beam element, and the string modeled with one truss element, comparable to Bellini's model. BSI\&2 was a similar model, except that the string was modeled using two beam elements with a very small moment of inertia $\left(1 \times 10^{-4}\right.$ in $\left.^{4}\right)$, similar to the string elements in the NASTRAN model. Similarly, BS2\&2 and BS4\&4 included two beam, two string, and four beam, four string elements, respectively.

Table 2 compares the maximum displacements for various meshes. The displacements were calculated using the output natural frequencies and mode shapes generated by the program BMSTRNG.FOR along with the program MODNEW.FOR, which solves for the displacements using a modal analysis and the Newmark Beta algorithm. Using 10 beam and 10 string elements, and a distributed impulse load of $0.0114 \mathrm{lb} \mathrm{in}^{-1}$ on the string (case a), yielded a maximum deflection of 6.50548 in at $t=2.0740 \mathrm{~s}$. For a concentrated end load on the beam of $1.0 \mathrm{lb}$ (case b), the maximum deflection of 1.04029 in occurred at $t=1.2988 \mathrm{~s}$. This table shows the effects of mesh fidelity on the response.

\section{DATA RECOVERY METHODOLOGY}

As an example, the shear and moment at the fixed end were calculated for case (b) $\left[F(t)=0.0114 \mathrm{lb} \mathrm{in}^{-1}\right]$ using the partitioned stiffness and mass matrices for the BS1\&2 model. The basic data recovery equation is

$$
R_{\mathrm{c}}=M_{\mathrm{ca}} \ddot{U}_{\mathrm{a}}+K_{\mathrm{ca}} U_{\mathrm{a}},
$$

where the subscripts $\mathrm{c}$ and a correspond to the constrained and active partitions of the stiffness and mass matrices, or

$$
\begin{aligned}
{\left[\begin{array}{l}
R 1 \\
R 2 \\
R 3
\end{array}\right]=} & {\left[\begin{array}{llllll}
M 14 & M 15 & M 16 & M 17 & M 18 & M 19 \\
M 24 & M 26 & M 27 & M 27 & M 28 & M 29 \\
M 34 & M 35 & M 36 & M 37 & M 38 & M 39
\end{array}\right]\left[\begin{array}{l}
U 4 \\
U 5 \\
U 6 \\
U 7 \\
U 8 \\
U 9
\end{array}\right] } \\
& +\left[\begin{array}{lllllll}
K 14 & K 15 & K 16 & K 17 & K 18 & K 19 \\
K 24 & K 25 & K 26 & K 27 & K 28 & K 29 \\
K 34 & K 35 & K 36 & K 37 & K 38 & K 39
\end{array}\right]\left[\begin{array}{l}
U 4 \\
U 5 \\
U 6 \\
U 7 \\
U 8 \\
U 9
\end{array}\right] .
\end{aligned}
$$

At $t=1.9244 \mathrm{~s}$, which was very close to the time of maximum displacement for this model,

$$
U=\left[\begin{array}{c}
0 \\
22.7333 \\
0.0122955 \\
0 \\
6.42438 \\
0.00723321
\end{array}\right] \quad \ddot{U}=\left[\begin{array}{c}
0 \\
-31.2392 \\
-0.0419784 \\
0 \\
-20.1476 \\
-0.102311
\end{array}\right]
$$




$$
\begin{gathered}
\mathrm{M}_{\mathrm{ca}}=\left[\begin{array}{cccccc}
0.07599 & 0 & 0 & 0.13 & 0 & 0 \\
0 & 0.05862 & -9.251 & 0 & 0.1003 & -31.64 \\
0 & 9.251 & -1399 & 0 & 31.64 & -9573
\end{array}\right] \\
\begin{array}{c}
K_{\mathrm{ca}}= \\
\text { elast. } \\
\text { only } \\
0
\end{array} \quad\left[\begin{array}{cccccc}
-533.1 & 0 & 0 & -7704 & 0 & 0 \\
0 & -0.00004303 & 0.0141 & 0 & -5.858 & 3840 \\
0 & -0.0141 & 3.082 & 0 & -3840 & 1,678,000
\end{array}\right] \\
{\left[\begin{array}{c}
R x \\
R y \\
M A
\end{array}\right]=\left[\begin{array}{c}
0 \\
-10.0858 \\
-12,421
\end{array}\right] .}
\end{gathered}
$$

If one includes $\left[K_{g}\right]$ during data recovery,

$$
\begin{gathered}
K_{\text {ca }}=\left[\begin{array}{cccccc}
-533.1 & 0 & 0 & -7704 & 0 & 0 \\
0 & -0.2746 & 15.01 & 0 & -5.72 & 3825 \\
0 & -15.01 & -3274 & 0 & -3825 & 1,684,000
\end{array}\right] \\
{\left[\begin{array}{c}
R x \\
R y \\
M A
\end{array}\right]=\left[\begin{array}{c}
0 \\
-15.3650 \\
-12,662
\end{array}\right] .}
\end{gathered}
$$

When the output from BSI\&2 are entered directly into the program REACTION.FOR to perform the above calculations, one obtains

$$
\left[\begin{array}{c}
R x \\
R y \\
M A
\end{array}\right]=\left[\begin{array}{c}
0 \\
-15.336943 \\
-12,656.83
\end{array}\right] \text {. }
$$

This slight discrepancy between the manual and computer calculation is due to the difference in precision between the calculations. The difference between the results obtained depending on whether $K_{\mathrm{g}}$ was included in data recovery, however, were extremely significant. For the above example (BS1\&2),

$$
\begin{array}{lccc} 
& K_{\mathrm{e}} \text { only } & K_{\mathrm{e}}+K_{\mathrm{g}} & \% \text { difference } \\
R x & 0 & 0 & 0 \% \\
R y & -10.0858 & -15.336943 & 34.4 \% \\
M A & -12,421 . & -12,656.82 & 1.9 \%
\end{array}
$$

The time histories of the shear and moment at the support for BS10\& 10 were calculated, both including and omitting $\left[K_{\mathrm{g}}\right]$ in the data recovery. The maximum moment at the fixed support, which occurred at $t=1.9562 \mathrm{~s}$, is $12,806.5 \mathrm{in}-1 \mathrm{~b}$ when $\left[K_{\mathrm{e}}\right]+\left[K_{\mathrm{g}}\right]$ is used in the calculation, and $12,696.7 \mathrm{in}-\mathrm{lb}$ when $\left[K_{\mathrm{e}}\right]$ only is used (a difference of $0.85 \%$ ). The maximum shear (vertical reaction) at the fixed support is $17.6325 \mathrm{lb}$, vs $10.5069 \mathrm{lb}$ when only $\left[K_{\mathrm{e}}\right]$ is included (a difference of $40.41 \%$ ).
The response of the BS10\&10 model is presented in Figs 4-7. Figure 4 shows the displacement along the beam at $t=1.9652 \mathrm{~s}$ and Fig. 5 plots the tip displacement vs time. Figures 6 and 7 present the moment and shear at the support with respect to time, respectively, and illustrate the significance of the results depending on whether or not $K_{\mathrm{g}}$ is included during data recovery.

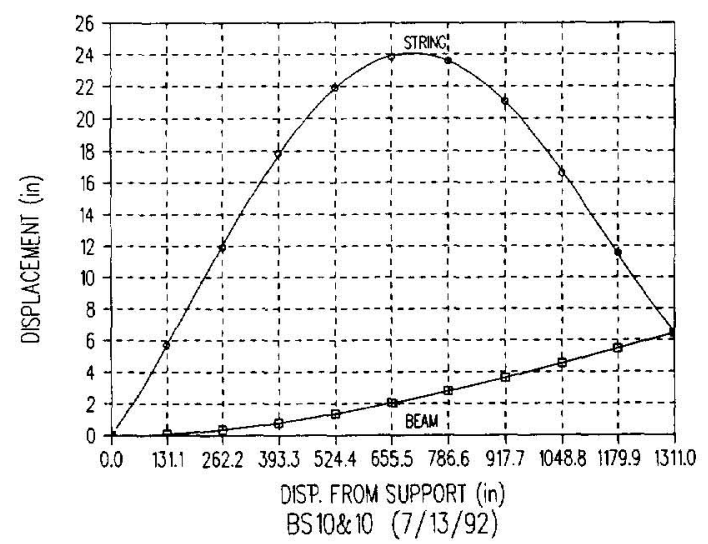

Fig. 4. Displacement at $T=1.9652 \mathrm{~s}$. 


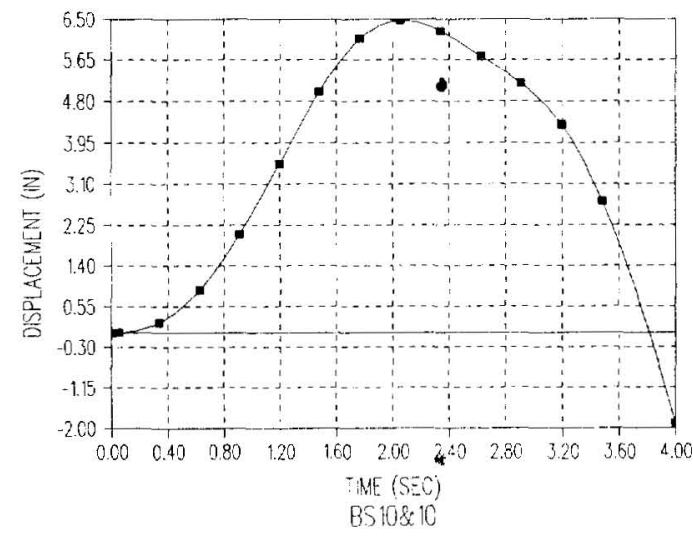

Fig. 5. Tip displacement.

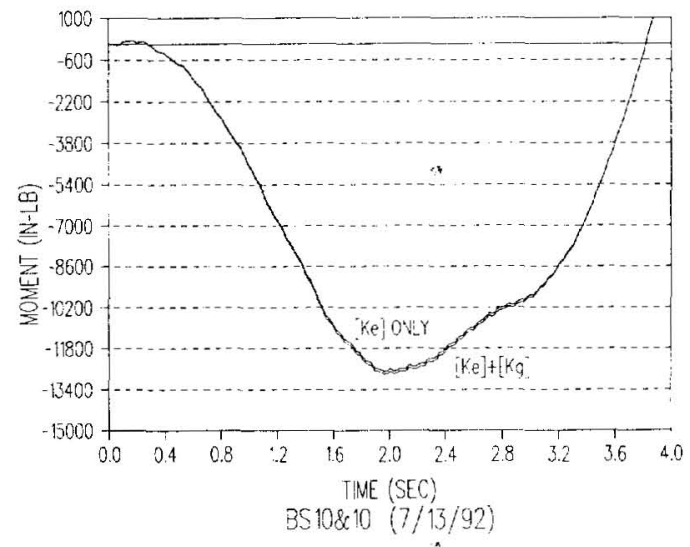

Fig. 6. Moment at support vs time.

\section{COMPARISON WITH MSC/NASTRAN 20 ELEMENT MODEL}

Table 3 compares these results with $\mathrm{MSC}_{i}$ NASTRAN, which includes $K_{g}$ determining the dynamic response, but neglects the $K_{\mathrm{g}}$ contribution during data recovery. Since the MSC/NASTRAN 20 element model includes some damping, and the maximums occur when $t>t_{0}$, it is expected that the results obtained will be slightly lower, as is the case.

Results indicate that the moment at the support, and subsequent bending stresses for this problem, are relatively unaffected by the omission of $\left[K_{\mathrm{g}}\right]$ from the data recovery (less than $1 \%$ low). The vertical reaction at the support is significantly affected $(40.4 \%$ low) when $\left[K_{\mathrm{g}}\right]$ is omitted. As previously indicated,

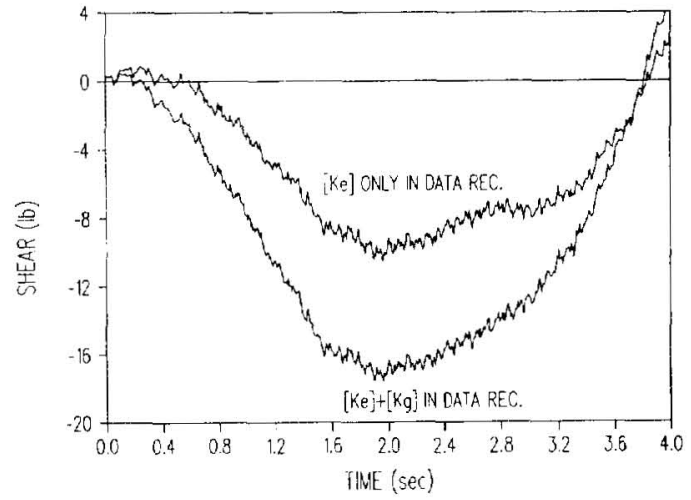

Fig. 7. Shear at support vs time

the difference between BS10\&10 neglecting $K_{\mathrm{g}}$, and the NASTRAN 20 element model may be partially attributed to the inclusion of slight damping in the model.

The relatively large difference in the vertical reaction (shear) at the support is due to the fact that the contribution from the displacement of the string (which is relatively large) is neglected when $K_{\mathrm{g}}$ is omitted during data recovery. The pre-load in the beam does not significantly affect the shear because the deflection of the beam itself is much smaller $(6.424$ in compared to 22.733 in or $28.25 \%$ ), and the contribution to the shear caused by rotation of the beam tip acts in the opposite direction. The affect on the moment is insignificant since the pre-load in the string is directed toward the support. Hence, it has no moment contribution.

It should be noted that the author's calculations in Table 3 correspond to the loads on the attachment point, and not the loads on the individual elements. In order to illustrate the effects on the individual elements, the three element static case was investigated.

\section{DATA RECOVERY-STATIC ANALYSIS}

As an aid in gaging the reasonableness of the results of the dynamic analysis, suppose one considers the idealized photo-voltaic array in Fig. 1, but statically applies a distributed load of $0.0114 \mathrm{lb} \mathrm{in}^{-1}$ to the string. The finite element for one beam and two string elements would be

Table 3. Comparison of results

\begin{tabular}{lccccc}
\hline & \multicolumn{2}{c}{$\begin{array}{c}\text { BMSTRNG.FOR } \\
\text { (BS10\&10) }\end{array}$} & & \multicolumn{2}{c}{ Chien (NASTRAN) } \\
& {$\left[K_{\mathrm{c}}\right]+\left[K_{\mathrm{g}}\right]$} & {$\left[K_{\mathrm{c}}\right]$ only } & & sol 72 & sol 69 \\
\hline Max tip displacement & 6.50548 & 6.50548 & & 5.9164 & 6.380 \\
Max bending moment at fixed support & $12,806.5$ & 12.696 .7 & & 11,492 & 12,395 \\
Max shear at fixed support & 17.6325 & 10.5069 & & 8.79 & 9.465 \\
\hline
\end{tabular}




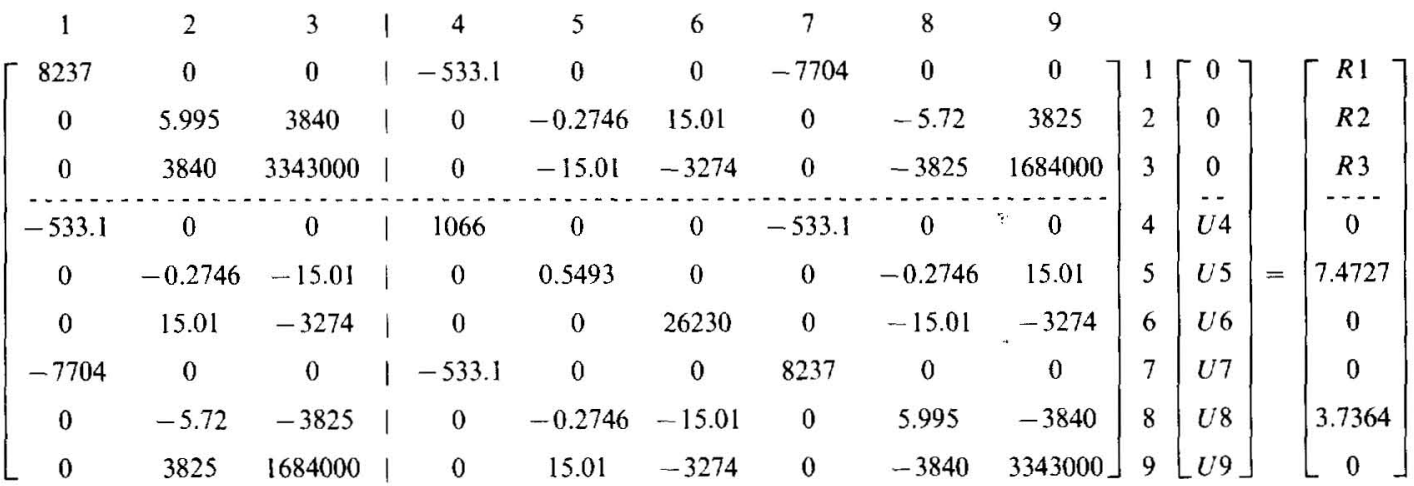

$$
\begin{aligned}
& {\left[K_{\mathrm{T}}\right] \quad\{U\} \quad\{R\}}
\end{aligned}
$$

In terms of the partitioned matrices in the data recovery equation, this becomes

$$
\left[\begin{array}{cccccc}
4 & 5 & 6 & 7 & 8 & 9 \\
1066 & 0 & 0 & -533.1 & 0 & 0 \\
0 & 0.5493 & 0 & 0 & -0.2746 & 15.01 \\
0 & 0 & 26230 & 0 & -15.01 & -3274 \\
-533.1 & 0 & 0 & 8237 & 0 & 0 \\
0 & -0.2746 & -15.01 & 0 & 5.995 & -3840 \\
0 & 15.01 & -3274 & 0 & -3840 & 3343000
\end{array}\right] \begin{gathered}
4 \\
5 \\
7 \\
8 \\
9
\end{gathered}\left[\begin{array}{c}
U 4 \\
U 5 \\
U 6 \\
U 7 \\
U
\end{array}\right]=\left[\begin{array}{c}
0 \\
7.4727 \\
0 \\
0 \\
3.7364 \\
0
\end{array}\right]
$$

Multiplying both sides by $[K]^{-1}$ yields

$$
\begin{aligned}
& \begin{array}{llllll}
4 & 5 & 6 & 7 & 8 & 9
\end{array} \\
& \left.\left[\begin{array}{cccccc}
9.694110^{-4} & 0 & 0 & 6.2743110^{-5} & 0 & 0 \\
0 & 1.97137 & 2.2896010^{-4} & 0 & 0.322283 & 3.5997110^{-4} \\
0 & 2.3014910^{-4} & 3.8482210^{-5} & 0 & 4.9335810^{-4} & 6.0335410^{-7} \\
6.2743110^{-5} & 0 & 0 & 1.2546410^{-4} & 0 & 0 \\
0 & 0.323109 & 4.9335710^{-4} & 0 & 0.689580 & 7.9112310^{-4} \\
0 & 3.6251910^{-4} & 6.0336410^{-7} & 0 & 7.9113910^{-4} & 1.2068410^{-6}
\end{array}\right] \begin{array}{c}
4 \\
5 \\
8 \\
9 \\
0 \\
0 \\
3.7364 \\
0
\end{array}\right] \\
& {\left[\begin{array}{l}
U 4 \\
U 5 \\
U 6 \\
U 7 \\
U 8 \\
U 9
\end{array}\right]=\left[\begin{array}{c}
0 \\
15.9356 \\
0.00356322 \\
0 \\
4.99104 \\
0.00566501
\end{array}\right]}
\end{aligned}
$$

The reactions are found as follows:

$$
\begin{aligned}
{\left[\begin{array}{l}
R 1 \\
R 2 \\
R 3
\end{array}\right]=} & {\left[\begin{array}{cccccc}
4 & 5 & 6 & 7 & 8 & 9 \\
-533.1 & 0 & 0 & -7704 & 0 & 0 \\
0 & -0.2746 & 15.01 & 0 & -5.72 & 3825 \\
0 & -15.01 & -3724 & 0 & -3825 & 1684000
\end{array}\right] 3 } \\
& =\left[\begin{array}{c}
0 \\
-11.2025 \\
-9802
\end{array}\right]
\end{aligned}
$$



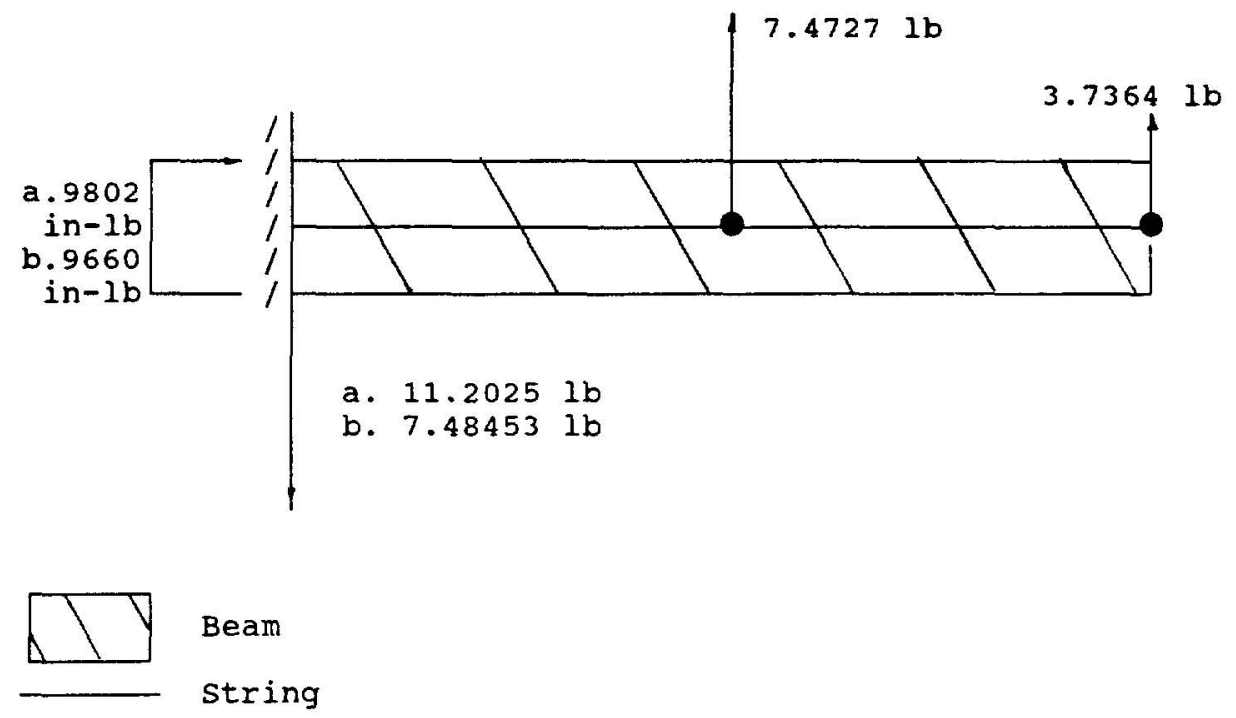

a. Using [Ke] $+[\mathrm{Kg}]$
b. [Kg] omitted

Fig. 8. Applied loads and reactions.

If one omits $\left[K_{\mathrm{g}}\right]$ during data recovery

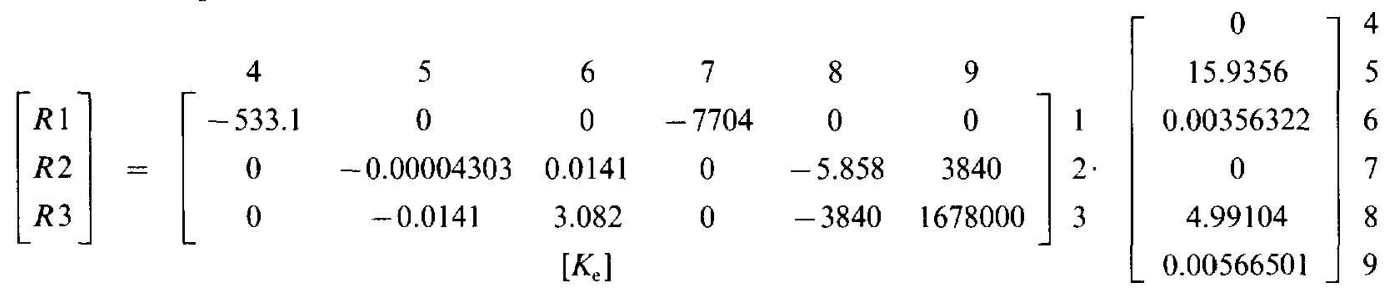

$$
\begin{aligned}
& =\left[\begin{array}{c}
0 \\
-7.48453 \\
-9660
\end{array}\right] \\
& \{U\}
\end{aligned}
$$

Figure 8 shows the applied effective loads (due to the distributed load on the string) and associated reactions. It should be noted that in the latter case $\left(\left[K_{\mathrm{g}}\right]\right.$ omitted during data recovery $)$, the structure is no longer in equilibrium. Suppose one considers each element separately. For beam one using $\left[K_{\mathrm{e}}\right]+\left[K_{\mathrm{g}}\right]$,

$$
\begin{aligned}
& \left.\left[\begin{array}{l}
R 1 \\
R 2 \\
R 3 \\
R 7 \\
R 8 \\
R 9
\end{array}\right]=\left[\begin{array}{cccccc}
1 & 2 & 3 & 7 & 8 & 9 \\
7704 & 0 & 0 & -7704 & 0 & 0 \\
0 & 5.72 & 3825 & 0 & -5.72 & 3825 \\
0 & 3825 & 3330000 & 0 & -3825 & 1684000 \\
-7704 & 0 & 0 & 7704 & 0 & 0 \\
0 & -5.72 & -3825 & 0 & 5.72 & -3825 \\
0 & 3825 & 1684000 & 0 & -3825 & 3330000
\end{array}\right] \begin{array}{c}
1 \\
2 \\
3 \\
7 \\
8 \\
0.00566501
\end{array}\right] \\
& {\left[K_{\mathrm{T}}\right]} \\
& \{U\} \\
& =\left[\begin{array}{c}
0 \\
-6.88008 \\
-9550.66 \\
0 \\
6.88008 \\
-226.166
\end{array}\right] .
\end{aligned}
$$


If one omits $\left[K_{\mathrm{g}}\right]$,

$$
\begin{aligned}
{\left.\left[\begin{array}{l}
R 1 \\
R 2 \\
R 3 \\
R 7 \\
R 8 \\
R 9
\end{array}\right]=\left[\begin{array}{cccccc}
1 & 2 & 3 & 7 & 8 & 9 \\
7704 & 0 & 0 & -7704 & 0 & 0 \\
0 & 5.858 & 3840 & 0 & -5.858 & 3840 \\
0 & 3840 & 3356000 & 0 & -3840 & 1678000 \\
-7704 & 0 & 0 & 7704 & 0 & 0 \\
0 & -5.858 & -3840 & 0 & 5.858 & -3840 \\
0 & 3840 & 1678000 & 0 & -3840 & 3356000
\end{array}\right] \begin{array}{l}
1 \\
2 \\
3 \\
7 \\
8 \\
0 \\
0 \\
-7.48387 \\
-9659.5 \\
0 \\
7.48387 \\
-153.5
\end{array}\right] } \\
\end{aligned}
$$

For string element one using $\left[K_{\mathrm{c}}\right]+\left[K_{\mathrm{g}}\right]$,

$$
\begin{aligned}
{\left.\left[\begin{array}{l}
R 1 \\
R 2 \\
R 3 \\
R 4 \\
R 5 \\
R 6
\end{array}\right]=\left[\begin{array}{cccccc}
1 & 2 & 3 & 4 & 5 & 6 \\
533.1 & 0 & 0 & -533.1 & 0 & 0 \\
0 & 0.2746 & 15.01 & 0 & -0.2746 & 1501 \\
0 & 15.01 & 13120 & 0 & -15.01 & -3274 \\
-5331 & 0 & 0 & 533.1 & 0 & 0 \\
0 & -0.2746 & -15.01 & 0 & 0.2746 & -15.01 \\
0 & 15.01 & -3274 & 0 & -15.01 & 13120
\end{array}\right] \begin{array}{c}
1 \\
2 \\
3 \\
5
\end{array}\right]\left[\begin{array}{c}
0 \\
0 \\
0 \\
0 \\
-4.32243 \\
-250.859 \\
0 \\
4.32243 \\
-192.443
\end{array}\right] . }
\end{aligned}
$$

If one considers $\left[K_{\mathrm{c}}\right]$ only,

$$
\begin{aligned}
{\left[\begin{array}{l}
R 1 \\
R 2 \\
R 3 \\
R 4 \\
R 5 \\
R 6
\end{array}\right]=\left[\begin{array}{ccccccc}
1 & 2 & 3 & 4 & 5 & 6 \\
533.1 & 0 & 0 & -533.1 & 0 & 0 & 1 \\
0 & 0.00004303 & 0.0141 & 0 & -0.00004303 & 0.0141 & 2 \\
0 & 0.0141 & 6.163 & 0 & -0.0141 & 3.082 & 3 \\
-533.1 & 0 & 0 & 533.1 & 0 & 0 & 4 \\
0 & -0.00004303 & -0.0141 & 0 & 0.00004303 & -0.0141 \\
0 & 0.0141 & 3.082 & 0 & -0.0141 & 6.163
\end{array}\right] 6 } \\
\cdot\left[\begin{array}{c}
0 \\
0 \\
0 \\
0 \\
15.9356 \\
0.00356322
\end{array}\right]=\left[\begin{array}{c}
0 \\
-6.3547210^{-4} \\
-0.213710 \\
0 \\
6\} \\
6.3547210^{-4} \\
-0.202731
\end{array}\right] .
\end{aligned}
$$


If one considers $\left[K_{\mathrm{e}}\right]+\left[K_{\mathrm{g}}\right]$ for string element two,

$$
\begin{aligned}
{\left.\left[\begin{array}{l}
R 4 \\
R 5 \\
R 6 \\
R 7 \\
R 8 \\
R 9
\end{array}\right]=\left[\begin{array}{cccccccc}
4 & 5 & 6 & 7 & 8 & 9 \\
533.1 & 0 & 0 & -533.1 & 0 & 0 \\
0 & 0.2746 & 15.01 & 0 & -0.2746 & 1501 \\
0 & 15.01 & 13120 & 0 & -15.01 & -3274 \\
-533.1 & 0 & 0 & 533.1 & 0 & 0 & 5 \\
0 & -0.2746 & -15.01 & 0 & 0.2746 & -15.01 \\
0 & 15.01 & -3274 & 0 & -15.01 & 13120
\end{array}\right] \cdot \begin{array}{c}
0 \\
15.9356 \\
0.00356322 \\
0 \\
0 \\
3.14390 \\
192.480 \\
0 \\
-3.14390 \\
226.937
\end{array}\right] . }
\end{aligned}
$$

Similarly, if one considers $\left[K_{\mathrm{e}}\right]$ only,

$$
\begin{aligned}
{\left.\left[\begin{array}{l}
R 4 \\
R 5 \\
R 6 \\
R 7 \\
R 8 \\
R 9
\end{array}\right]=\left[\begin{array}{cccccc}
4 & 5 & 6 & 7 & 8 & 9 \\
533.1 & 0 & 0 & -533.1 & 0 & 0 \\
0 & 0.00004303 & 0.0141 & 0 & -0.00004303 & 0.0141 \\
0 & 0.0141 & 6.163 & 0 & -0.0141 & 3.082 \\
-533.1 & 0 & 0 & 533.1 & 0 & 0 \\
0 & -0.00004303 & -0.0141 & 0 & 0.00004303 & -0.0141 \\
0 & 0.0141 & 3.082 & 0 & -0.0141 & 6.163
\end{array}\right] \begin{array}{c}
4 \\
5 \\
0 \\
0 \\
0.90356322 \\
0 \\
0.00566501 \\
\{U\}
\end{array}\right]=\left[\begin{array}{c}
0 \\
6.0106610^{-4} \\
0.193738 \\
0 \\
-6.0106610^{-4} \\
0.200214
\end{array}\right] }
\end{aligned}
$$

Table 4. Comparison of reactions and element forces

\begin{tabular}{lccc}
\hline & {$\left[K_{\mathrm{e}}\right]+\left[K_{\mathrm{g}}\right]$} & {$\left[K_{\mathrm{e}}\right]$ only } & $\%$ Difference \\
\hline Horizontal reaction at support & 0 & 0 & 0 \\
Vertical reaction at support & -11.2025 & -7.48453 & -32.2 \\
Moment at support & -9802 & -9660 & -1.4 \\
Beam element one & 0 & & 0 \\
$R 1^{*}$ & -6.88008 & -7.48387 & +8.1 \\
$R 2$ & -9550.66 & -9659.5 & +1.1 \\
$R 3$ & 0 & 0 & 0 \\
$R 7^{*}$ & 6.88008 & 7.48387 & +8.8 \\
$R 8$ & -226.166 & -153.5 & -32.1 \\
$R 9$ & & & \\
String element one & 0 & 0 & -100 \\
$R 1^{*}$ & -4.32243 & $-6.35 \times 10^{-4}$ & -100 \\
$R 2$ & -250.859 & -0.213710 & 0 \\
$R 3$ & 0 & 0 & 100 \\
$R 4^{*}$ & 4.32243 & $6.35 \times 10^{-4}$ & -99.9 \\
$R 5$ & -192.443 & -0.202731 & \\
$R 6$ & & & 0 \\
String element two & 0 & 0 & -100 \\
$R 4^{*}$ & 3.14390 & $6.01 \times 10^{-4}$ & 0 \\
$R 5$ & 192.480 & 0.193738 & -100 \\
$R 6$ & 0 & 0 & -99.9 \\
$R 7^{*}$ & -3.14390 & $-6.01 \times 10^{-4}$ & \\
$R 8$ & 226.937 & 0.200214 & \\
$R 9$ & & & \\
\hline
\end{tabular}

*Calculated force $=0$, although applied force $P=150 \mathrm{lb}$. 
a. Using [Ke] + [Kg] During Data Recovery
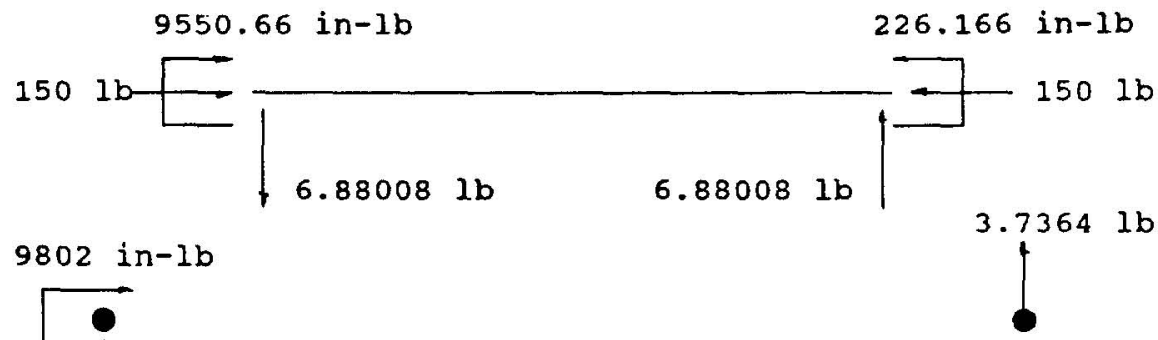

$1.20251 \mathrm{~b}$

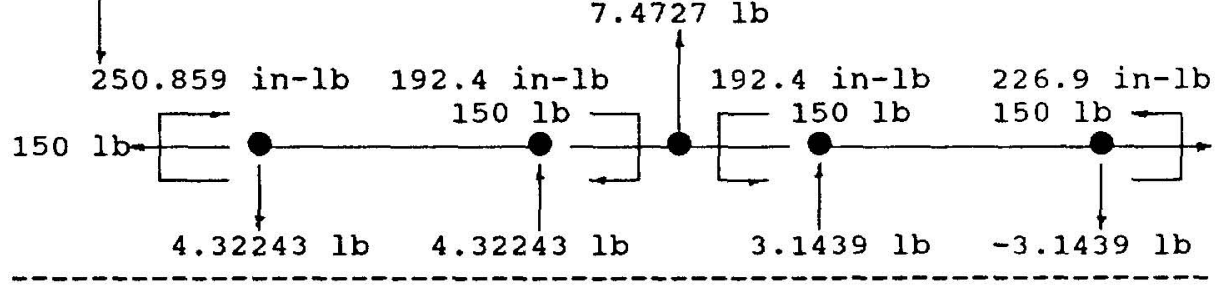

b. Using [Ke] Only During Data Recovery
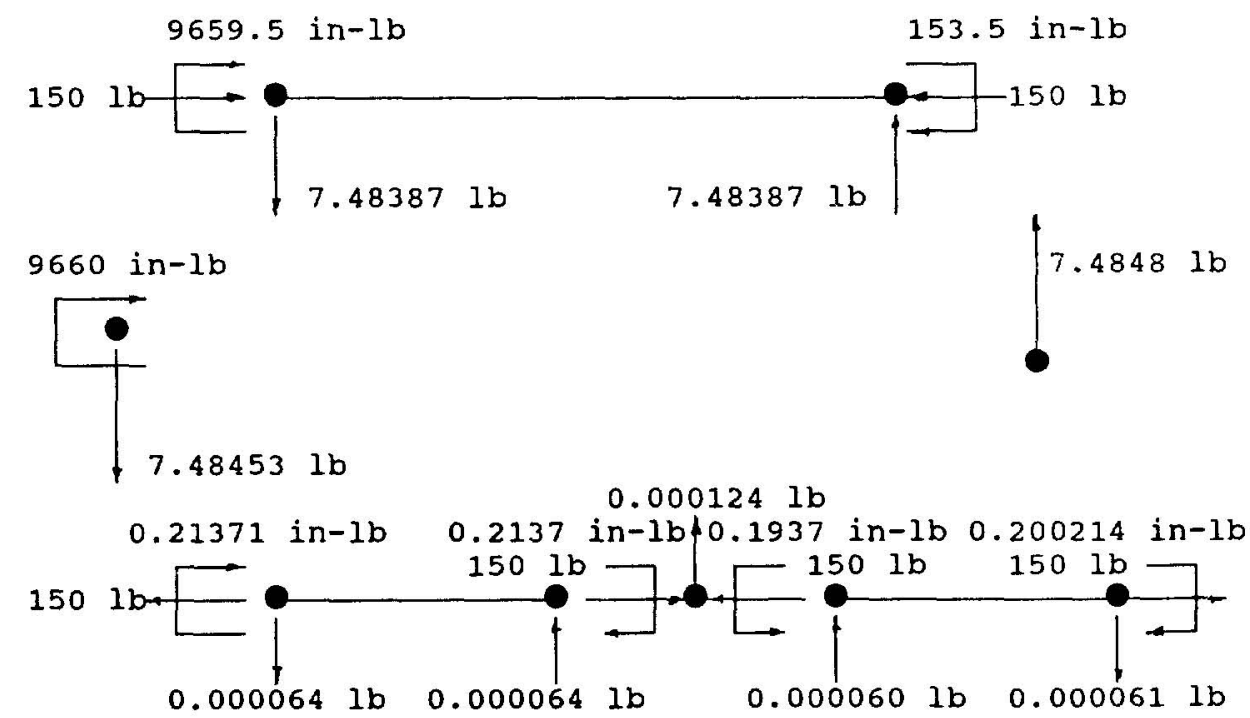

Fig. 9. Shear and moment on each element.

The results are presented in Fig. 9 and Table 4.

\section{RESULTS OF STATIC ANALYSIS}

For this idealized static load problem, omitting $\left[K_{\mathrm{g}}\right]$ during data recovery causes significant underestimation of the vertical (shear) load at the fixed support $(-32.2 \%)$, as well as the end shears of the string elements (end shears essentially undetected). The moment obtained at the support is very close to the actual value using $\left[K_{\mathrm{e}}\right]+\left[K_{\mathrm{g}}\right](-1.4 \%)$. The end shears of the beam element are slightly conservative $(8.8 \%$ high). The presence of similar discrepancies would be expected for the impulse loads with the various meshes. The relative closeness of the results for the static and dynamic load cases support the "reasonableness" of the prior dynamic analysis.

\section{CONCLUSION AND RECOMMENDATION}

As the results of this analysis clearly indicate, the neglect of the geometric stiffness terms during data recovery may cause significant error in the calculation of shear stress. This occurs regardless of whether geometric stiffness was included during the calculation of the displacements. When analyzing a structure with pre-loaded components, one should always consider the contribution of the preload to the stiffness by including the geometric stiffness terms during all phases of the analysis; calculation of free 
vibration frequencies and mode shapes, dynamic response, and subsequent determination of bending and shear forces and stresses.

\section{REFERENCES}

1. P. Bosela, F. Shaker and D. Fertis, Dynamic analysis of space-related linear and non-linear structures. Comput. Struct. 44, 1145-I148 (1992).
2. P. Bosela, D. Fertis and F. Shaker, Grounding of space structures. Comput. Struct. 45, 143-153 (1992).

3. P. Bosela, D. Feitis and F. Shaker, A new pre-loaded beam geometric stiffness matrix with full rigid body capabilities. Comput. Struct. 45, 155-163 (1992).

4. F. Shaker, Effect of axial load on mode shapes and frequencies of beams. NASA TN D.8109 (1975).

5. K. Carney and F. Shaker, Free vibration characteristics and correlation of a space station split-blanket solar array. NASA TX 101452 (1989).

Post-print standardized by MSL Academic Endeavors, the imprint of the Michael Schwartz Library at Cleveland State University, 2014 